\title{
Review of the possible association between thyroid and breast carcinoma
}

\author{
Liangbo Dong, Jun Lu, Bangbo Zhao, Weibin Wang ${ }^{*}$ and Yupei Zhao ${ }^{*}$
}

\begin{abstract}
Background: Thyroid and breast cancer are two of the malignant diseases with highest incidence in females. Based on clinical experience, breast and thyroid cancer often occur metachronously or synchronously. Therefore, thyroid and breast cancer might share some common etiological factors. The relationship between these diseases has attracted substantial attention, and because these two glands are both regulated by the hypothalamic-pituitary axis, such a relationship is not surprising. A study of this relationship will be useful for obtaining a better understanding of the mechanism by which these two malignancies co-occur.

Main body: This study reviewed the progress in research on the roles of iodine intake, folate metabolism, obesity, gonadal hormones, and thyroid hormone in thyroid and breast cancer. These studies evaluating the etiological roles of these factors in linking breast and thyroid cancer might also improve our understanding and identify new therapeutic approaches, such as sodium/iodide symporter-mediated radioiodine therapy and thyroid-stimulating hormone receptor antagonists, for breast cancer. In addition, some specific treatments for each cancer, such as radiotherapy for breast cancer or radioactive iodine therapy for thyroid cancer, might be risk factors for secondary malignances, including breast and thyroid cancer.
\end{abstract}

Conclusions: Studies of the precise relationship between the co-occurrence of breast and thyroid cancer will certainly improve our understanding of the biological behaviors of these two malignancies and direct evidencebased clinical practice.

Keywords: Thyroid cancer, Breast cancer, lodine, Sodium iodide symporter, Thyroid hormone, Thyroid hormone receptor, Gonadal hormone, Obesity, Radioactive iodide therapy

\section{Background}

The thyroid and mammary glands are both regulated by the hypothalamic-pituitary axis. Based on clinical experience, patients were diagnosed with breast and thyroid cancer metachronously or synchronously more frequently than expected by accident. However, their mechanisms of action remain unknown. Are these two common malignancies in women related? Several studies have detected a possible association between these malignancies. Jee Hyun An, Yul Hwangbo, et al. carried out a retrospective case-control study that suggested that the overall risk of second primary thyroid cancer (TC) or breast cancer (BC) is significantly increased in patients who previously had BC or TC, respectively [1]. Previous studies have also

\footnotetext{
*Correspondence: wwb_xh@163.com; zhao8028@263.net Department of General Surgery, Peking Union Medical College Hospital, Chinese Academy of Medical Science and Peking Union Medical College, Beijing 100730, People's Republic of China
}

confirmed this finding [2-5]. As the genesis and development of TC and $\mathrm{BC}$ are associated, researchers must investigate the causes of these types of multiple primary tumors (MPTs). This study reviewed the recent progress in research on the roles of iodine intake, folate metabolism, obesity, gonadal hormones, thyroid hormone, and signaling pathways in thyroid and breast cancer.

\section{lodide}

lodide, iodine transport, and breast cancer

There is overlap between TC and BC regarding the uptake and utilization of dietary iodine. Several studies have focused on the role of iodine in BC. Hypothyroidism and low iodine intake may be important preventable etiological factors in estrogen-dependent tumors of the breast, uterus, and ovary. Iodine supplementation may lead to a decreased incidence of these cancers in future generations. The sodium/iodine symporter (NIS), a large integral

(c) The Author(s). 2018 Open Access This article is distributed under the terms of the Creative Commons Attribution 4.0 International License (http://creativecommons.org/licenses/by/4.0/), which permits unrestricted use, distribution, and 
plasma membrane glycoprotein that mediates iodide uptake, is expressed at its highest levels in the thyroid and lactating breast [6-8]. Over 40 years ago, BC tissues were shown to take up radioactive iodine; in contrast, uptake does not occur in normal, non-lactating breast tissues [9]. 25 years later, NIS mRNA was first detected in breast cancer specimens [10]. In 2001, Moon DH, Lee SH, et al. studied the correlation between the expression of the human NIS mRNA and the uptake of 99mTc-pertechnetate in 25 breast tumors. However, compared with NIS mRNA expression, the level of iodide uptake was relatively low [11]. Later, in 2003, the NIS protein was shown to be predominantly expressed in the intracellular space, whereas NIS in lactating mammary glands is located on the basolateral membrane [6]. Therefore, researchers have hypothesized that the mislocalization of NIS protein may lead to the disparity between the NIS expression level and observed radioiodide uptake. Based on endocrinological studies, iodine deficiency may stimulate the gonadotrophin secretion and then result in a hyperestrogenic state, which possesses characteristics of relatively high production of estrone and estradiol and a relatively low estriol to estrone and estradiol ratio. This alteration in endocrine state may increase the risk of $\mathrm{BC}$ [12]. In addition, strategies that increase dietary iodine intake may reduce the risk of BC [13] (Fig. 1). Conversely, excess iodide intake also plays an unfavorable role in $\mathrm{BC}$ by stimulating ER- $\alpha$ transcriptional activity [14]. Malya FU et al. reported a high urine-iodine concentration (UIC) in a significantly larger portion of $\mathrm{BC}$ patients than controls [15]. Others have also indicated that NIS can be used as an objective criterion for predicting the sensitivity of luminal $B$ and basal $\mathrm{BC}$ subtypes to neoadjuvant chemotherapy, which will improve treatment outcomes in this group of patients [16].

\section{lodine, iodide transport, and thyroid cancer}

Iodine deficiency is a well-established risk factor for the development of TC, [17] and iodine supplementation has been carried out in most areas with endemic goiter. Chronic iodine deficiency may have some protective effects on females, but no equivalent studies have detected its effect on males [18]. As shown in the study by Anne-Catherine Gerard et al., iodine deficiency induces the expression of the vascular endothelial growth factor (VEGF) mRNA in both normal thyroid cells and TC cells. This effect lasts longer in thyroid carcinoma cell lines, suggesting impairment of downregulation mechanism. Moreover, the iodine deficiency-induced VEGF expression partially depends on hypoxia-inducible factor-1 (HIF-1) instead of on reactive oxygen species. Thus, iodine deficiency may provide an angiogenic environment for abnormal proliferation of TC cells [19]. By contrast,

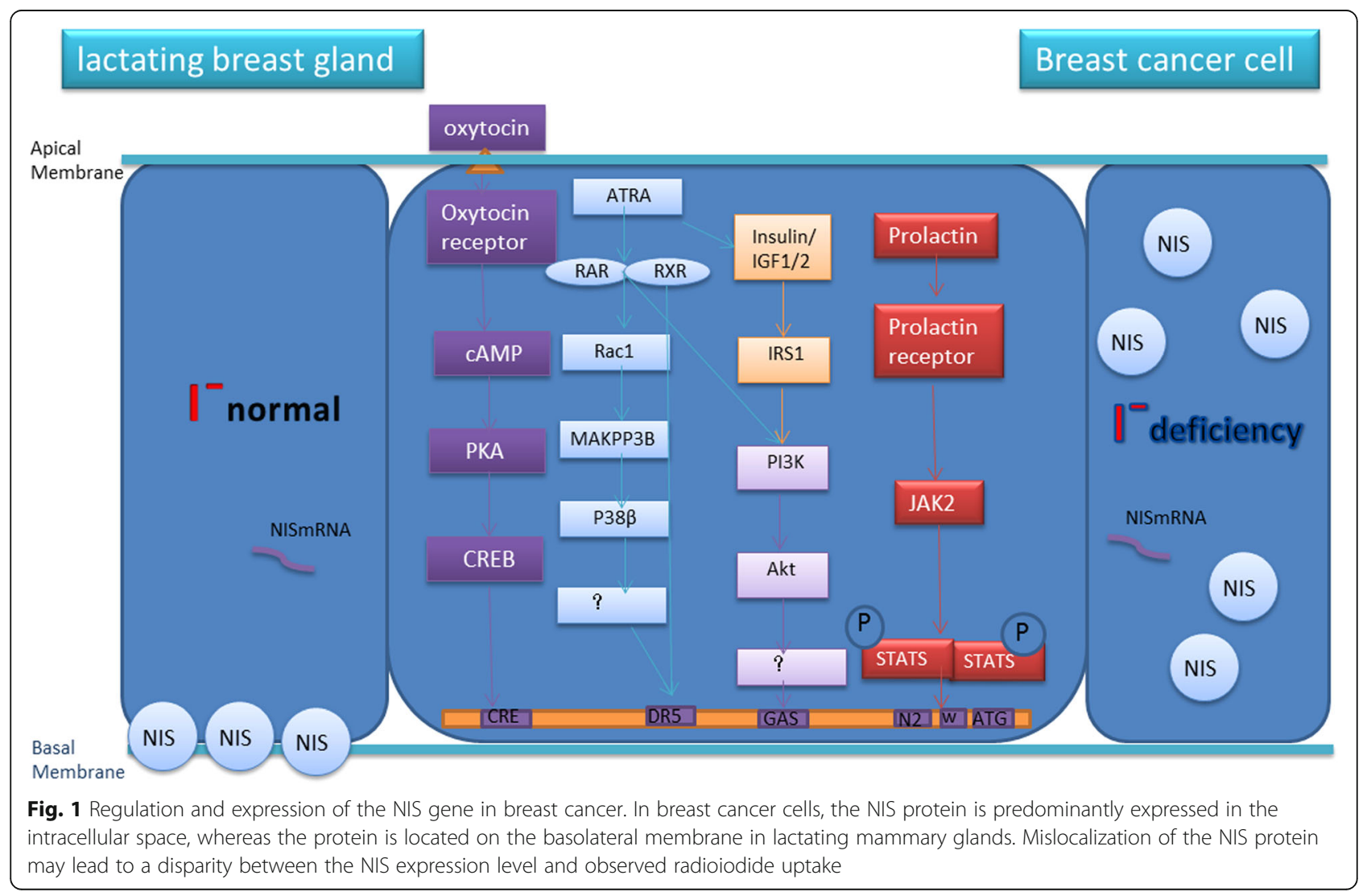


excess iodine has also been connected with an increased incidence of papillary thyroid cancer (PTC). After the implementation of universal salt iodization in China in 1996, the incidence of goiter was reduced by almost $50 \%$; however, the incidence of TC is steadily increasing [20]. Haixia Guan from Johns Hopkins Hospital and others have focused on this issue and initiated a study measuring and comparing the mutation of the T1799A BRAF in 1032 patients from five regions in China with different levels of iodine intake. As high iodine intake contributes to the occurrence of the T1799A BRAF gene mutation, it may be a risk factor for the development of PTC [21]. According to a cross-sectional study from South China, the mean UIC, an index for evaluating the nutritional status of a population, is significantly higher in patients with thyroid nodules than in healthy individuals; of these thyroid nodules, approximately 5-15\% were malignant, i.e., TC [22]. However, the conclusive link between excess iodide and TC remains unclear. Others also believe that this increase in the incidence is mainly due to advances in diagnostic technology.

In conclusion, dietary iodide deficiency and intracellular iodide deficiency caused by mislocalization of NIS may play a role in the carcinogenesis of $\mathrm{TC}$ and $\mathrm{BC}$. Iodine deficiency may cause DNA damage in the thyroid gland and promote cancer [23]. Moreover, studies on the role of iodide in $\mathrm{BC}$ provide promising therapeutic approaches. For instance, NIS-mediated radioiodine therapy for estrogen receptor-negative $\mathrm{BC}$ has been studied in more detail [24], and Kelkar MG recently reported that histone deacetylase inhibitors (HDACis) as modulators of NIS expression can significantly increase NIS expression but do not alter its intracellular localization. Thus, there is a promising future for NIS-mediated radioiodine therapy [25]. Kelkar MG, first highlighted the role of p53 as a negative transcriptional regulator of human functional NIS gene expression in $\mathrm{BC}$, providing important perspectives into the promising clinical use of NIS-mediated radioiodine therapy, which may significantly impact a patient with a mutant versus wild-type p53 profile [26].

\section{Sex hormones, reproductive factors, and thyroid cancer}

Hormones induce oncogenesis by promoting cell proliferation, an essential component of carcinogenesis. In addition, their important roles have been well studied in $\mathrm{BC}$ and prostate cancers [27]. TC exhibits a great gender disparity; it is 2.9-fold more common in women than in men. A significant difference between men and women is their sex hormones and the influences of these hormones on multiple organs and systems. The fluctuating levels of sex hormones during a woman's menstrual cycle and pregnancy have been hypothesized to be the root cause of the gender disparity in PTC [28]. Because
TC is highly prevalent in fertile women, hormonal and reproductive factors may also be involved in its incidence [29]. As shown in the 1993 study by Inoue et al., estradiol increases proliferation of estrogen receptor (ER)-positive PTC, supporting the hypothesis that estrogen promotes the proliferation of this type of disease [30]. Estradiol also alters the expression of estrogen receptor subtypes in TC cell lines [31-33]. Guia et al. investigated the expression of estrogen receptor $\alpha(E R \alpha)$ and progesterone receptor (PR) in female and male patients with PTC and connected their levels with the clinical manifestation and molecular features. ER $\alpha$ and PR were detected in 66.5 and $75.8 \%$ of cases, respectively. Their expression significantly relates to a larger tumor size and higher prevalence of local metastases. Furthermore, the "receptor conversion" (variation in receptor status in primary and metastatic $\mathrm{BC}$ ) phenomenon was first observed in thyroid cancer and has subsequently been reported in BC [29]. Estrogen promotes growth through classical genomic and non-genomic pathways, which are mediated via the membrane-bound ER. This receptor is correlated to the Aurora-like serine/threonine kinase (APK) and phosphoinositol 3-kinase (PI3K) tyrosine kinase signaling pathways. However, in contrast to other carcinomas, detailed information about this regulatory mechanism has not been reported for TC [34]. As shown in the study by Rajoria et al., estrogen is associated with increased adherence, invasion, and migration of TC cell lines. Thus, the higher occurrence rate of TC in women could possibly due to the expression of a functional ER, which participates in cellular processes that contribute to the enhanced mitogenic, migratory, and invasive potential of thyroid cells. These findings will promote the future development of anti-estrogenic therapies targeting neoplasm invasion and migration, thus reducing the tendency to metastasize [35]. Membrane-bound ER is linked to the mitogen-activated protein kinase (MAPK) and PI3K tyrosine kinase signaling pathways, and in PTC, these pathways may be activated by either chromosomal rearrangement of the tyrosine receptor kinase (TRKA), RET/PTC genes, or a BRAF mutation. Additionally, these pathways may be stimulated by high estrogen levels in females. Furthermore, estrogen regulates angiogenesis and metastasis, which are crucial to the outcomes of TC [34].

\section{Thyroid hormones (THs), TH receptor $\beta 1$ (TR $\beta 1$ ), antibodies, and breast cancer \\ THs}

Thyroid hormones exert diverse critical biological effects on the growth, differentiation, metabolism, and physiological function of almost all human tissues, including the mammary gland [36, 37]. However, the correlation between thyroid function and BC is uncertain. Søgaard M, Farkas 
DK, et al. conducted a nationwide cohort study, which included 61,873 women with hypothyroidism and 80,343 women with hyperthyroidism, in which the women with hyperthyroidism had greater risk of developing $\mathrm{BC}$, and the women with hypothyroidism had a slightly decreased incidence of BC [38]. By evaluating a large cohort of women, Journy NMY et al. also reported that the risk of BC mortality elevated in women with hyperthyroidism with hyperthyroidism after 60 years of age [39]. Others have already focused on the mechanism underlying this phenomenon. As reported in the study by Moretto FC, De Sibio MT, et al., triiodothyronine (T3) may induce the expression of HIF-1 and transform growth factor alpha (TGF) in the MCF7 breast cancer cell line. These factors are related to the genesis and development of BC. Moreover, thiiodothyronine (T3) exerts this effect by activating PI3K [40]. As shown in the 2002 study by Sumi Dinda et al., T3 may regulate the cell cycle progression and proliferation of T47D cells (an estrogen-responsive human ductal carcinoma cell line that expresses detectable levels of ER) by increasing the p53 levels and inducing pRb hyperphosphorylation via a common mechanism involving the ER and T3 receptor-mediated pathways [41]. Additionally, Hall LC et al. supported this hypothesis and reported that T3 induced activation of ER-mediated gene expression and promoted the proliferation of MCF7 cells. Although the effects were weaker than those induced by E2, T3 may play roles in $\mathrm{BC}$ development and progression [42]. In the 2010 study by Tosovic A et al., the T3 levels were shown to be positively and dose-dependently related to the $\mathrm{BC}$ risk in postmenopausal women [43]. The 2005 study by P.P. Saraiva also supported the above conclusion that high T3 levels in postmenopausal women are positively and dose-dependently correlated with the risk of $\mathrm{BC}$. However, this situation was observed in postmenopausal women who had a significant increase in their thyroid/estradiol ratio. These phenomena may suggest that the imbalance between E2 and T3 promotes the genesis and development of BC [44]. In contrast, hypothyroidism has been associated with a decreased risk of $\mathrm{BC}$ [45]. However, the association between $\mathrm{TH}$ and $\mathrm{BC}$ is currently controversial, and conclusive evidence is lacking. In a study by Johannes LP et al., hypothyroidism and low-normal free T4 (FT4) levels were reported to be correlated to an increased risk of $\mathrm{BC}$ in postmenopausal women [46]. Overall, further studies are needed to investigate the precise association between thyroid function and $\mathrm{BC}$.

\section{TR}

TR belongs to the nuclear hormone receptor superfamily, similar to classical biomarkers of BC, such as ER and $\mathrm{PR}$. Its exact role in the genesis and progression of $\mathrm{BC}$ has been known for years. Several scientists investigated this question in 2014. As demonstrated in the study by
Sobine Heublein, Doris Mayr, et al., TRs may be an interesting biomarker and prognostic factor for patients with BRCA1-associated BC. TR $\beta$ positivity may be positively related to the five-year or overall survival of $\mathrm{BC}$ patients, whereas TR $\alpha$ has opposing actions [47]. Jeon won Park et al. studied the mutation of $\operatorname{TR} \beta$, which is considered to have oncogenic activity. According to previous studies, TR $\beta 1$ may function as a tumor suppressor. However, TR $\beta 1$ expression is silenced by several mechanisms, such as hypermethylation of the promoter region and a microRNA-mediated regulatory mechanism. Additionally, TR $\beta 1$ mutations also cause it to lose its tumor suppressor function. In addition to the C-terminal frameshift mutation $\mathrm{PV}$, some additional sequences in the C-terminal regions of TR $\beta 1$, such as Mkar, Mdbs, and AM, also exhibit oncogenic activity, promoting cell proliferation and suppressing differentiation and apoptosis [48]. Some researchers in China have reported that aberrant TR $\beta 1$ expression and mutations are associated with the genesis and development of $\mathrm{BC}$ in the Chinese population [49]. Nonetheless, the exact role of TR in the genesis of $\mathrm{BC}$ remains unclear. Further studies are needed to identify a new biomarker of $\mathrm{BC}$ and new strategies for developing targeted therapy.

As discussed above, altered $\mathrm{TH}$ function and dysfunction of TR contribute to the increased incidence of BC. Other factors, such as autoimmune antibodies, may also play a role in its genesis [50]. Autoimmune thyroid diseases, such as Graves' disease, are characterized by increased levels of thyroid peroxidase antibodies (TPOAbs) and thyroglobulin antibodies (TgAbs). These two autoimmune antibodies have a well-established association with BC. In addition, Pawel S. et al. in 2013 showed the TSH receptor (TSHR) antibody to be a positive determinant of $\mathrm{BC}$ and the only positive determinant in the analysis of age-matched patients. Thus, TSHR antagonists may potentially play a prophylactic role in $\mathrm{BC}$, and additional clinical research is advisable [51].

\section{Others}

The genesis and development of both TC and BC are quite complicated. Some other factors may play a role in the co-existence of $\mathrm{TC}$ and $\mathrm{BC}$. Radioactive iodine therapy is a routine therapy for differentiated TC in Western countries, and it is increasingly being used in China. As mentioned above, mammary gland cells also express NIS, thus, the breast tissue may also absorb radioactive iodine, and the absorption of a high dose of radioactive substances may induce carcinogenesis [52]. The results of a retrospective single-center study in Portugal suggest that the risk of developing second primary cancer is increased after radioactive iodine therapy, particularly for activities $>200 \mathrm{mCi}$ [53]. However, because of the lack of statistics, this hypothesis requires further support. 
Additionally, in a 2015 long-term follow-up study, radioactive iodine (RAI) therapy did not significantly increase the occurrence and recurrence of subsequent $\mathrm{BC}$ [54]. In 2015, Zhang YJ et al. from Peking Union Medical College conducted a meta-analysis that included 6 cohort studies, involving 17,914 patients. The results suggested that the risk of secondary primary $\mathrm{BC}$ in $\mathrm{TC}$ survivors treated with RAI did not increase compared with TC survivors not treated with RAI [55]. Folate metabolism, which plays an essential role in DNA synthesis, is another important aspect of carcinogenesis, and it was recently shown to be involved in the increased incidence of TC and BC. As shown in a study by Zara-Lopes T, an alteration in the methylenetetrahydrofolate reductase (MTHFR) gene that participates in folate metabolism, C677T, is significantly associated with the increased incidence of thyroid and breast cancer. These factors may be used as potential predictive and prognostic markers for both types of cancer [56]. Obesity and a higher cancer risk have a well-established, strong association; weight, weight gain, and obesity are responsible for approximately $20 \%$ of all malignant neoplasms. TC and BC are no exception [57]. A 2016 study in Korea reported a positive association between a high body mass index (BMI) and TC incidence, and prevention efforts, such as weight gain control, may reduce the burden of TC [58]. Yunji Hwang et al. conducted a large-scale case-control study and suggested that middle-aged adults who gain weight have a higher risk of developing PTC. Although this study has some limitations, such as recall and detection bias, the results still suggest that weight gain control can decrease the incidence of TC [59]. A study in France also supported this hypothesis. Clavel-Chapelon $\mathrm{F}$ et al. identified a significant dose-dependent association between the risk of developing TC and BMI, particularly in women who gained weight from menarche to adulthood [60]. Meanwhile, the role of obesity or a high BMI in the development of breast cancer has been well-known for years [61, 62]. Moreover, weight loss interventions are recommended for patients with $\mathrm{BC}$ [63].

\section{Conclusions}

In summary, the etiologies of thyroid and mammary gland cancers share common features, such as iodine intake and transport and the levels of thyroid function, TH receptors, obesity, and sex hormones. Factors that contribute to the initiation of TC, such as low dietary iodine, hypothyroidism, and other thyroid disorders, may also contribute to the increased risk of BC. Some factors, such as estrogen and reproductive factors that play well-established roles in BC initiation, may be associated with TC. These studies may help to explain why these two cancers occur metachronously or synchronously more frequently than would be expected by chance. Moreover, studies on the commonalities between these two cancers may provide new prophylactic therapeutic strategies and early diagnostic methods, such as anti-estrogen therapy for thyroid carcinoma and anti-TSHR therapy for breast carcinoma. Although further theoretical and clinical studies are still needed before these treatments are applied in the clinic, future clinical applications are promising. The precise relationship between the co-occurrence of breast and thyroid cancer remains controversial and inconclusive, yet studies of their co-occurrence will certainly improve our understanding of the biological behaviors of these two malignancies and direct evidence-based clinical practice.

\section{Abbreviations}

BC: Breast cancer; MPTs: Multiple primary tumors; NIS: Sodium/iodide symporter; PTC: Papillary thyroid cancer; TC: Thyroid cancer; TH: Thyroid hormone; TR $\beta 1$ : TH receptor $\beta 1$; TSH: Thyroid stimulating hormone; TSHR: Thyroid-stimulating hormone receptor

\section{Funding}

The Research Special Fund for the Public Welfare Industry of Health (The Translational Research of Early Diagnosis and Comprehensive Treatment in Pancreatic Cancer, 201202007)

\section{Authors' contributions}

$L D, J L$, and BZ wrote the paper. $Y Z$ and $W W$ were involved in reviewing and editing the manuscript. All authors read and approved the final manuscript.

\section{Authors' information \\ Zhao Yupei, male, is an academician of the Chinese Academy of Sciences, chief surgeon, 18 and 19 central alternate member, vice chairman of the China Association for Science and Technology, deputy director of the Central Health Committee, Peking Union Medical College Hospital, and vice president of the Chinese Medical Association. He has been working in the front-line of clinical work, scientific research and teaching in general surgery. He has won the second prize of national science and technology progress.}

Ethics approval and consent to participate

Not applicable.

Consent for publication

Not applicable.

Competing interests

The authors declare that they have no competing interests.

\section{Publisher's Note}

Springer Nature remains neutral with regard to jurisdictional claims in published maps and institutional affiliations.

Received: 4 March 2018 Accepted: 26 June 2018

Published online: 05 July 2018

\section{References}

1. An JH, Hwangbo Y, Ahn HY, Keam B, Lee KE, Han W, Park do J, Park IA, Noh DY, Youn YK, et al. A possible association between thyroid cancer and breast cancer. Thyroid. 2015;25:1330-8.

2. Brown AP, Chen J, Hitchcock YJ, Szabo A, Shrieve DC, Tward JD. The risk of second primary malignancies up to three decades after the treatment of differentiated thyroid cancer. J Clin Endocrinol Metab. 2008;93:504-15.

3. Subramanian S, Goldstein DP, Parlea L, Thabane L, Ezzat S, Ibrahim-Zada I, Straus S, Brierley JD, Tsang RW, Gafni A, et al. Second primary malignancy risk in thyroid cancer survivors: a systematic review and meta-analysis. Thyroid. 2007;17:1277-88.

4. Tanaka H, Tsukuma H, Koyama H, Kinoshita Y, Kinoshita N, Oshima A. Second primary cancers following breast cancer in the Japanese female population. Jpn J Cancer Res. 2001;92:1-8. 
5. Evans HS, Lewis CM, Robinson D, Bell CM, Moller H, Hodgson SV. Incidence of multiple primary cancers in a cohort of women diagnosed with breast cancer in Southeast England. Br J Cancer. 2001;84:435-40.

6. Wapnir IL, van de Rijn M, Nowels K, Amenta PS, Walton K, Montgomery K, Greco RS, Dohan O, Carrasco N. Immunohistochemical profile of the sodium/iodide symporter in thyroid, breast, and other carcinomas using high density tissue microarrays and conventional sections. J Clin Endocrinol Metab. 2003:88:1880-8.

7. Tazebay UH, Wapnir IL, Levy O, Dohan O, Zuckier LS, Zhao QH, Deng HF, Amenta PS, Fineberg S, Pestell RG, Carrasco N. The mammary gland iodide transporter is expressed during lactation and in breast cancer. Nat Med. 2000;6:871-8.

8. Cho JY, Leveille R, Kao R, Rousset B, Parlow AF, Burak WE Jr, Mazzaferri EL, Jhiang SM. Hormonal regulation of radioiodide uptake activity and $\mathrm{Na}+/ /$ symporter expression in mammary glands. J Clin Endocrinol Metab. 2000;85: 2936-43.

9. Eskin BA, Parker JA, Bassett JG, George DL. Human breast uptake of radioactive iodine. Obstet Gynecol. 1974;44:398-402.

10. Kilbane MT, Ajjan RA, Weetman AP, Dwyer R, McDermott EW, O'Higgins NJ, Smyth PP. Tissue iodine content and serum-mediated 125I uptake-blocking activity in breast cancer. J Clin Endocrinol Metab. 2000:85:1245-50.

11. Moon DH, Lee SJ, Park KY, Park KK, Ahn SH, Pai MS, Chang H, Lee HK, Ahn IM. Correlation between 99mTc-pertechnetate uptakes and expressions of human sodium iodide symporter gene in breast tumor tissues. Nucl Med Biol. 2001;28:829-34.

12. Rappaport J. Changes in dietary iodine explains increasing incidence of breast Cancer with distant involvement in young women. J Cancer. 2017:8:174-7.

13. Smyth PP. The thyroid, iodine and breast cancer. Breast Cancer Res. 2003;5: 235-8.

14. He S, Wang B, Lu X, Miao S, Yang F, Zava T, Ding Q, Zhang S, Liu J, Zava D, Shi YE. lodine stimulates estrogen receptor singling and its systemic level is increased in surgical patients due to topical absorption. Oncotarget. 2018;9: 375-84.

15. Malya FU, Kadioglu H, Hasbahceci M, Dolay K, Guzel M, Ersoy YE. The correlation between breast cancer and urinary iodine excretion levels. J Int Med Res. 2018;46:687-92.

16. Chekhun VF, Andriiv AV, Lukianova NY. Significance of iodine symporter for prognosis of the disease course and efficacy of neoadjuvant chemotherapy in patients with breast cancer of luminal and basal subtypes. Exp Oncol. 2017;39:65-8.

17. Franceschi S. lodine intake and thyroid carcinoma-a potential risk factor Exp Clin Endocrinol Diabetes. 1998;106(Suppl 3):S38-44.

18. Zimmermann $M B$, Galetti V. lodine intake as a risk factor for thyroid cancer: a comprehensive review of animal and human studies. Thyroid Res. 2015;8:8

19. Gerard AC, Humblet K, Wilvers C, Poncin S, Derradji H, de Ville de Goyet C, Abou-el-Ardat K, Baatout S, Sonveaux P, Denef JF, Colin IM. Iodinedeficiency-induced long lasting angiogenic reaction in thyroid cancers occurs via a vascular endothelial growth factor-hypoxia inducible factor-1dependent, but not a reactive oxygen species-dependent, pathway. Thyroid. 2012;22:699-708.

20. Zhao W, Han C, Shi X, Xiong C, Sun J, Shan Z, Teng W. Prevalence of goiter and thyroid nodules before and after implementation of the universal salt iodization program in mainland China from 1985 to 2014: a systematic review and meta-analysis. PLoS One. 2014;9:e109549.

21. Guan H, Ji M, Bao R, Yu H, Wang Y, Hou P, Zhang Y, Shan Z, Teng W, Xing M. Association of high iodine intake with the T1799A BRAF mutation in papillary thyroid cancer. J Clin Endocrinol Metab. 2009;94:1612-7.

22. Zhao H, Tian Y, Liu Z, Li X, Feng M, Huang T. Correlation between iodine intake and thyroid disorders: a cross-sectional study from the south of China. Biol Trace Elem Res. 2014:162:87-94.

23. Maier J, van Steeg H, van Oostrom C, Paschke R, Weiss RE, Krohn K. lodine deficiency activates antioxidant genes and causes DNA damage in the thyroid gland of rats and mice. Biochim Biophys Acta. 2007;1773:990-9.

24. Yao C, Pan Y, Li Y, Xu X, Lin Y, Wang W, Wang S. Effect of sodium/iodide symporter (NIS)-mediated radioiodine therapy on estrogen receptornegative breast cancer. Oncol Rep. 2015;34:59-66.

25. Kelkar MG, Senthilkumar K, Jadhav S, Gupta S, Ahn BC, De A. Enhancement of human sodium iodide symporter gene therapy for breast cancer by HDAC inhibitor mediated transcriptional modulation. Sci Rep. 2016;6:19341.
26. Kelkar MG, Thakur B, Derle A, Chatterjee S, Ray P, De A. Tumor suppressor protein p53 exerts negative transcriptional regulation on human sodium iodide symporter gene expression in breast cancer. Breast Cancer Res Treat. 2017:164:603-15.

27. Pathak DR, Osuch JR, He J. Breast carcinoma etiology: current knowledge and new insights into the effects of reproductive and hormonal risk factors in black and white populations. Cancer. 2000;88:1230-8.

28. Rahbari R, Zhang L, Kebebew E. Thyroid cancer gender disparity. Future Oncol. 2010;6:1771-9.

29. Vannucchi G, De Leo S, Perrino M, Rossi S, Tosi D, Cirello V, Colombo C, Bulfamante G, Vicentini L, Fugazzola L. Impact of estrogen and progesterone receptor expression on the clinical and molecular features of papillary thyroid cancer. Eur J Endocrinol. 2015:173:29-36.

30. Inoue H, Oshimo K, Miki H, Kawano M, Monden Y. Immunohistochemical study of estrogen receptors and the responsiveness to estrogen in papillary thyroid carcinoma. Cancer. 1993;72:1364-8.

31. Lee ML, Chen GG, Vlantis AC, Tse GM, Leung BC, van Hasselt CA. Induction of thyroid papillary carcinoma cell proliferation by estrogen is associated with an altered expression of BCl-xL. Cancer J. 2005;11:113-21.

32. Zeng $\mathrm{Q}$, Chen $\mathrm{GG}$, Vlantis $\mathrm{AC}$, van Hasselt CA. Oestrogen mediates the growth of human thyroid carcinoma cells via an oestrogen receptor-ERK pathway. Cell Prolif. 2007:40:921-35.

33. Zeng $Q$, Chen G, Vlantis A, Tse G, van Hasselt C. The contributions of oestrogen receptor isoforms to the development of papillary and anaplastic thyroid carcinomas. J Pathol. 2008;214:425-33.

34. Derwahl M, Nicula D. Estrogen and its role in thyroid cancer. Endocr Relat Cancer. 2014;21:T273-83.

35. Rajoria S, Suriano R, Shanmugam A, Wilson YL, Schantz SP, Geliebter J, Tiwari RK. Metastatic phenotype is regulated by estrogen in thyroid cells. Thyroid. 2010;20:33-41.

36. Cheng SY, Leonard JL, Davis PJ. Molecular aspects of thyroid hormone actions. Endocr Rev. 2010:31:139-70.

37. Yen PM. Physiological and molecular basis of thyroid hormone action. Physiol Rev. 2001:81:1097-142.

38. Sogaard M, Farkas DK, Ehrenstein V, Jorgensen JO, Dekkers OM, Sorensen HT. Hypothyroidism and hyperthyroidism and breast cancer risk: a nationwide cohort study. Eur J Endocrinol. 2016;174:409-14.

39. Journy NMY, Bernier MO, Doody MM, Alexander BH, Linet MS, Kitahara CM. Hyperthyroidism, hypothyroidism, and cause-specific mortality in a large cohort of women. Thyroid. 2017;27:1001-10.

40. Moretto FC, De Sibio MT, Luvizon AC, Olimpio RM, de Oliveira M, Alves CA, Conde SJ, Nogueira CR. Triiodothyronine (T3) induces HIF1A and TGFA expression in MCF7 cells by activating PI3K. Life Sci. 2016;154:52-7.

41. Dinda S, Sanchez A, Moudgil V. Estrogen-like effects of thyroid hormone on the regulation of tumor suppressor proteins, p53 and retinoblastoma, in breast cancer cells. Oncogene. 2002;21:761-8.

42. Hall LC, Salazar EP, Kane SR, Liu N. Effects of thyroid hormones on human breast cancer cell proliferation. J Steroid Biochem Mol Biol. 2008;109:57-66.

43. Tosovic A, Bondeson AG, Bondeson L, Ericsson UB, Malm J, Manjer 」. Prospectively measured triiodothyronine levels are positively associated with breast cancer risk in postmenopausal women. Breast Cancer Res. 2010;12:R33.

44. Saraiva PP, Figueiredo NB, Padovani CR, Brentani MM, Nogueira CR. Profile of thyroid hormones in breast cancer patients. Braz J Med Biol Res. 2005:38:761-5.

45. Cristofanilli M, Yamamura Y, Kau SW, Bevers T, Strom S, Patangan M, Hsu L, Krishnamurthy S, Theriault RL, Hortobagyi GN. Thyroid hormone and breast carcinoma. Primary hypothyroidism is associated with a reduced incidence of primary breast carcinoma. Cancer. 2005;103:1122-8.

46. Kuijpens JL, Nyklictek I, Louwman MW, Weetman TA, Pop VJ, Coebergh JW. Hypothyroidism might be related to breast cancer in post-menopausal women. Thyroid. 2005;15:1253-9.

47. Heublein S, Mayr D, Meindl A, Angele M, Gallwas J, Jeschke U, Ditsch N. Thyroid hormone receptors predict prognosis in BRCA1 associated breast Cancer in opposing ways. PLoS One. 2015;10:e0127072.

48. Park JW, Zhao L, Willingham M, Cheng SY. Oncogenic mutations of thyroid hormone receptor beta. Oncotarget. 2015;6:8115-31.

49. Ling $Y$, Ling $X$, Fan L, Wang $Y$, Li Q. Mutation analysis underlying the downregulation of the thyroid hormone receptor beta1 gene in the Chinese breast cancer population. Onco Targets Ther. 2015;8:2967-72.

50. Jiskra J, Limanova Z, Barkmanova J, Smutek D, Friedmannova Z. Autoimmune thyroid diseases in women with breast cancer and colorectal cancer. Physiol Res. 2004;53:693-702. 
51. Szychta P, Szychta W, Gesing A, Lewinski A, Karbownik-Lewinska M. TSH receptor antibodies have predictive value for breast cancer - retrospective analysis. Thyroid Res. 2013;6:8.

52. Goldman MB, Maloof F, Monson RR, Aschengrau A, Cooper DS, Ridgway EC Radioactive iodine therapy and breast cancer. A follow-up study of hyperthyroid women. Am J Epidemiol. 1988;127:969-80.

53. Silva-Vieira M, Carrilho Vaz S, Esteves S, Ferreira TC, Limbert E, Salgado L, Leite V. Second primary Cancer in patients with differentiated thyroid cancer: does radioiodine play a role? Thyroid. 2017;27:1068-76.

54. Ahn HY, Min HS, Yeo Y, Ma SH, Hwang Y, An JH, Choi HS, Keam B, Im SA, Park do J, et al. Radioactive iodine therapy did not significantly increase the incidence and recurrence of subsequent breast Cancer. J Clin Endocrinol Metab. 2015;100:3486-93.

55. Zhang Y, Liang J, Li H, Cong H, Lin Y. Risk of second primary breast cancer after radioactive iodine treatment in thyroid cancer: a systematic review and meta-analysis. Nucl Med Commun. 2016;37:110-5.

56. Zara-Lopes T, Gimenez-Martins AP, Nascimento-Filho CH, et al. Role of MTHFR C677T and MTR A2756G polymorphisms in thyroid and breast cancer development []]. Genet Mol Res. 2016;15(2).

57. Wolin KY, Carson K, Colditz GA. Obesity and cancer. Oncologist. 2010;15: 556-65.

58. Shin $\mathrm{HY}$, Yong $\mathrm{HJ}$, Cho ER. Body mass index and incidence of thyroid cancer in Korea: the Korean cancer prevention study-II. J Cancer Res Clin Oncol. 2016; 143(1):1-7.

59. Hwang Y, Lee KE, Park YJ, Kim SJ, Kwon H, Park do J, Cho B, Choi HC, Kang D, Park SK. Annual average changes in adult obesity as a risk factor for papillary thyroid cancer: a large-scale case-control study. Medicine (Baltimore). 2016:95:e2893.

60. Clavel-Chapelon F, Guillas G, Tondeur L, Kernaleguen C, Boutron-Ruault MC. Risk of differentiated thyroid cancer in relation to adult weight, height and body shape over life: the French E3N cohort. Int J Cancer. 2010;126:2984-90

61. Ligibel J. Obesity and breast cancer. Oncology (Williston Park). 2011;25:9941000.

62. Yung RL, Ligibel JA. Obesity and breast cancer: risk, outcomes, and future considerations. Clin Adv Hematol Oncol. 2016:14:790-7.

63. Reeves MM, Terranova CO, Eakin EG, Demark-Wahnefried W. Weight loss intervention trials in women with breast cancer: a systematic review. Obes Rev. 2014;15:749-68

\section{Ready to submit your research? Choose BMC and benefit from:}

- fast, convenient online submission

- thorough peer review by experienced researchers in your field

- rapid publication on acceptance

- support for research data, including large and complex data types

- gold Open Access which fosters wider collaboration and increased citations

- maximum visibility for your research: over $100 \mathrm{M}$ website views per year

At BMC, research is always in progress.

Learn more biomedcentral.com/submissions 